\title{
Stimulation programs for pediatric drug research - do children really benefit?
}

\author{
Isabelle Boots • Rám N. Sukhai • Richard H. Klein • \\ Robert A. Holl • Jan M. Wit • Adam F. Cohen • \\ Jacobus Burggraaf
}

Received: 26 September 2006 / Accepted: 16 November 2006 / Published online: 17 January 2007

(C) Springer-Verlag 2007

\begin{abstract}
Most drugs that are currently prescribed in pediatrics have not been tested in children. Pediatric drug studies are stimulated in the USA by the pediatric exclusivity provision under the Food and Drug Administration Modernization Act (FDAMA) that grants patent extensions when pediatric labeling is provided. We investigated the effectiveness of these programs in stimulating drug research in children, thereby increasing the evidence for safe and effective drug use in the pediatric population. All drugs granted pediatric exclusivity under the FDAMA were analyzed by studying the relevant summaries of medical and clinical pharmacology reviews of the pediatric studies or, if these were unavailable, the labeling information as provided by the manufacturer. A systematic search of the literature was performed to identify drug utilization patterns in children. From July 1998 to August 2006, 135 drug entities were granted pediatric exclusivity. Most frequent drug groups were anti-depressants and mood stabilizers, ACE inhibitors, lipid-lowering preparations, HIV antivirals, and non-steroidal anti-inflammatory and anti-rheumatic drugs. The distribution of the different drugs closely matched the distribution of these drugs over the adult market, and not the drug utilization by children.
\end{abstract}

In memory of Isabelle Boots, the primary contributor to this work, who unexpectedly passed away at the brink of a promising career.

I. Boots $\cdot$ R. N. Sukhai $\cdot$ R. H. Klein $\cdot$ R. A. Holl $\cdot$ J. M. Wit Department of Pediatrics, Leiden University Medical Center, Willem Alexander Kinder- en Jeugdcentrum, LUMC,

Postbus 9600,

2300 RC Leiden, The Netherlands

R. H. Klein · A. F. Cohen · J. Burggraaf $(\bowtie)$

Centre for Human Drug Research,

Leiden, The Netherlands

e-mail: kb@chdr.nl
Many drug studies in children have been performed since the introduction of the FDAMA. However, children infrequently use the drugs granted pediatric exclusivity. The priorities for pediatric drug research should be set by the need of the patients, not by market considerations.

Keywords Pediatrics · Pharmaceutical preparations . Clinical trials $\cdot$ Licensure $\cdot$ Patents

$\begin{array}{ll}\text { Abbreviations } \\ \text { ACE } & \text { angiotensin converting enzyme } \\ \text { ATC } & \text { anatomical therapeutical classification } \\ \text { EMEA } & \text { European Medicines Agency } \\ \text { EU } & \text { European Union } \\ \text { FDA } & \text { Food and Drug Administration } \\ \text { FDAMA } & \text { Food and Drug Administration Modernization Act } \\ \text { ICH } & \text { International Conference on Harmonization } \\ \text { ICU } & \text { intensive care unit } \\ \text { SPC } & \text { supplementary protection certificate } \\ \text { USA } & \text { United States of America } \\ \text { PUMA } & \text { Pediatric Use Marketing Authorization }\end{array}$

\section{Introduction}

Most drugs prescribed in pediatrics have not been tested in children. A recent review demonstrates that up to $80 \%$ of prescriptions for children in hospital and in general practice are either unlicensed (without a license for children) or used off-label (outside the product license) [15]. Of commercially available drugs in Europe, only 35\% are authorized for use in children [4]. Although there are reasons why children do not often participate in clinical trials, including ethical, scientific and commercial considerations [2, 25], it is 
considered unacceptable to treat children with drugs that have not been studied properly.

In 1997, the Food and Drug Administration (FDA) and the Congress introduced the Food and Drug Administration Modernization Act (FDAMA), and this was followed by the Best Pharmaceuticals for Children Act. Closely linked to this legislation is the Pediatric Rule (1998), which requires the industry to perform research in the pediatric population. In the European Union (EU), final legislation on this topic has been approved and will come into effect at the beginning of 2007 .

In both continents, the measures taken to address the problems broadly follow the same pattern. The first incentive is aimed at new medicines and intended for products covered by a patent or a supplementary protection certificate (SPC). For these drugs, a 6-month extension of market exclusivity is granted if a pediatric study is performed. The second incentive has the objective of increasing the knowledge on drugs that are no longer patent protected. In order to obtain the data necessary to establish safety, quality and efficacy specifically in children, either funding for the studies (USA) or market exclusivity (a so-called Pediatric Use Marketing Authorization-PUMA) can be given. Central to the second incentive is that experts are involved in determining for which drugs the greatest medical need exists and in ensuring that these drugs will be given priority. In the USA, the FDA plays this central role, and in the EU, a Pediatric Committee will be established within the European Medicines Agency (EMEA) which will be given a similar role.

The EU Commission apparently follows the approach in the USA with regard to patent-protected drugs because, according to the EU Commission, "the pediatric exclusivity provision has been extremely successful in the USA in stimulating the development of medicinal products for pediatric use" [1].

At the brink of implementing new programs (EU) or decisions on continuation of existing programs (USA), we questioned what the influence of the pediatric exclusivity regulation has been on pediatric drug development. We evaluated the drugs that are granted pediatric exclusivity in the USA by studying research that has been performed as a consequence of the exclusivity provision, and by comparing the drugs granted pediatric exclusivity with medicines actually used by children.

\section{Materials and methods}

The drugs granted pediatric exclusivity since the introduction of the FDAMA in July 1998 until August 2006 were retrieved from the FDA website [17]. All drugs were classified into subgroups according to the Anatomical Therapeutical Clas- sification (ATC) system of the European Pharmaceutical Marketing Research Association. The data submitted to the FDA that resulted in granting the exclusivity were examined. For each drug, the publicly available summaries of medical and clinical pharmacology reviews of the pediatric studies were scrutinized. These summaries contain information on the pediatric research performed to obtain pediatric exclusivity. If these summaries were unavailable, the labeling information of the drug with pediatric exclusivity was studied to retrieve information about the pediatric studies performed. Each drug label contains a pediatrics section stating whether the drug is tested in children and, if so, information on the performed studies is given $[6,17,26]$. Data were extracted about the type of study, number and age of participants, whether long-term follow-up (defined as $>1$ year with specific attention for long term effects on growth and development) was undertaken and whether the study led to a pediatric indication being included on the label. Participants were divided into pediatric age categories according to the International Conference on Harmonization (ICH) guidelines: neonates (birth-27 days), infants (28 days23 months), children (2-11 years) and adolescents (1218 years).

To obtain data about drug use in children, recently published surveys of drug prescribing in hospitals and general practice were reviewed by a systematic search of the literature on drugs used by children. Details on the literature search and selection criteria are provided in box 1. Drug use in adults was assessed by using the sales figures from public databases and publications thereof $[7,8]$. The data were categorized according to the ATC system as mentioned above.

Literature search and selection strategy

Step 1: literature searches of the PubMed and Embase bibliographic databases for papers published in English between 1990 and July 2005 combining the following search terms (keywords and appropriate medical subject headings):

- Child, preschool (or) child (or) infant (or) infant, newborn (or) adolescent (or) pediatric (or) paediatric (or) paediatrics.

- Pharmaceutical preparations (or) drugs, non-prescription (or) drugs, generic (or) drug, therapy (or) prescriptions, drug (or) medicine (or) medication.

- Drug utilization (or) pharmacoepidemiology (or) drug utilization review.

Step 2: the references contained in articles identified in step 1 were examined to identify further relevant studies.

Step 3: based on the titles and abstracts of the papers, we next identified and then located full-text copies of 35 potentially relevant studies for closer examination. 
Step 4: selection of articles by two independent reviewers (I.B., R.S.), using the following selection criteria:

- Study performed in the industrialized world, defined as in Europe, North America, Australia and New Zealand.

- Study population of children from 0 to at least 14 years, to include all age groups (neonates, infants, children and adolescents).

- Sufficient information in the paper about drug utilization to classify $90 \%$ of the drugs in an ATC drug groups.

- Avoidance of selection bias by exclusion of voluntary surveys.

Step 5: inclusion of nine papers meeting all selection criteria.

\section{Results}

Pediatric exclusivity provision

According to the FDA, 135 drugs (130 active moieties) were granted pediatric exclusivity from July 1998 to
August 2006. Most frequent drug groups were central nervous system drugs (19\%), such as anti-depressants and psycholeptics, cardiovascular drugs (16\%), mainly ACE inhibitors and lipid-lowering preparations, systemic antiinfectives (12\%), among which largely HIV antivirals, cytostatics $(11 \%)$, and alimentary tract medication $(12 \%)$, among which proton pump inhibitors and oral antihyperglycemic medication (Table 1).

From 118 drugs (91\%), information about studies performed in children to obtain pediatric exclusivity could be retrieved from the FDA summaries of medical and clinical pharmacology reviews $(n=61)$ of the pediatric studies or the prescribing information as provided by the manufacturer $(n=57)$. No information could be found on 12 of the drug entities, mainly including over the counter drugs. The product label of 13 drugs merely stated that safety and/or efficacy in the pediatric population had not been established. For the remaining 105 drugs, in total, 326 studies were performed for the approval of pediatric exclusivity. At least 40,075 pediatric patients participated in these 326 studies (the number of participants was not noted for 27 of these studies). In the majority of the

Table 1 Active moieties granted pediatric exclusivity according to ATC group

\begin{tabular}{|c|c|c|c|}
\hline Drug category & $\begin{array}{l}\text { Number of } \\
\text { drugs }(\% \text { of total) }\end{array}$ & Most frequent drug classes & $\begin{array}{l}\text { Number } \\
\text { of drugs }\end{array}$ \\
\hline \multirow[t]{5}{*}{ Central nervous system } & \multirow[t]{5}{*}{$24(19 \%)$} & Anti-depressants & 8 \\
\hline & & Psychostimulants, agents used for ADHD and nootropics & 4 \\
\hline & & Anti-epileptics & 3 \\
\hline & & General anaesthetics & 3 \\
\hline & & Anti-migraine preparations & 2 \\
\hline \multirow[t]{3}{*}{ Cardiovascular system } & \multirow[t]{3}{*}{$21(16 \%)$} & ACE inhibitors, plain & 6 \\
\hline & & HMG-CoA reductase inhibitors & 5 \\
\hline & & Beta-blocking agents & 4 \\
\hline \multirow[t]{2}{*}{ Alimentary tract and metabolism } & \multirow[t]{2}{*}{$16(12 \%)$} & Drugs for peptic ulcer and gastro-oesophageal reflux disease & 5 \\
\hline & & Oral blood glucose lowering drugs & 4 \\
\hline \multirow[t]{2}{*}{ Anti-infectives for systemic use } & \multirow[t]{2}{*}{$15(12 \%)$} & Direct acting antivirals & 10 \\
\hline & & Antibacterials for systemic use & 4 \\
\hline \multirow[t]{3}{*}{ Antineoplastic and immunomodulating agents } & \multirow[t]{3}{*}{$14(11 \%)$} & Other antineoplastic agents & 5 \\
\hline & & Antimetabolites & 3 \\
\hline & & Alkylating agents & 2 \\
\hline \multirow[t]{2}{*}{ Musculo-skeletal system } & \multirow[t]{2}{*}{$7(5 \%)$} & Anti-inflammatory and anti-rheumatic products, non-steroids & 6 \\
\hline & & Drugs affecting bone structure and mineralization & 1 \\
\hline \multirow[t]{3}{*}{ Respiratory system } & \multirow[t]{3}{*}{$10(8 \%)$} & Antihistamines for systemic use & 4 \\
\hline & & Drugs for obstructive airway disease & 3 \\
\hline & & Decongestants and other nasal preparations for topical use & 2 \\
\hline \multirow[t]{2}{*}{ Sensory organs } & \multirow[t]{2}{*}{$10(8 \%)$} & Antiglaucoma preparations and miotics & 4 \\
\hline & & Decongestants and anti-allergics & 3 \\
\hline Dermatologicals & $6(5 \%)$ & Corticosteroids, potent (group 3) & 3 \\
\hline Genito-urinary system and sex-hormones & $3(3 \%)$ & Other urologicals, including antispasmodics & 2 \\
\hline Blood and blood forming organs & $2(2 \%)$ & Anti-thrombotic agents & 1 \\
\hline Systemic hormonal preparations & $1(1 \%)$ & Hypothalamic hormones & 1 \\
\hline Parasitology & $1(1 \%)$ & Anti-malarials & 1 \\
\hline Total & $130(100 \%)$ & & \\
\hline
\end{tabular}


applications, children over a wide age range were included. Information on the age of participants was not provided for 54 of the 326 studies. Children participated in 224 of the remaining 272 studies $(82 \%)$, adolescents in $177(65 \%)$, infants were included in $105(39 \%)$ of the trials, and neonates in 38 trials $(14 \%)$. Only $1(0.4 \%)$ study included preterm infants. The objective of most $(62 \%)$ of the 326 studies was to determine the safety and efficacy of a drug. Pharmacokinetics and/or pharmacodynamics were studied in $147(45 \%)$ trials, efficacy-only in $13(4 \%)$ and safetyonly in $38(12 \%)$. From the 299 studies in which information about the number of participants was given, on average 134 children participated per study. This varied from 8 children in a safety and efficacy study of a HIV antiviral in neonates, to 994 children participating in a safety database of an antibiotic. Long-term ( $>1$ year) follow-up was either done or planned for $25(21 \%)$ of the 118 drugs.

For $42 \%$ of the drugs granted pediatric exclusivity and for which information was available (50 out of 118), the information obtained from the pediatric studies led to an approved pediatric indication.

The 130 active moieties granted pediatric exclusivity were categorized according to the ATC system. The results are shown in Table 1.

Drug utilization by children and adults

The search strategy retrieved nine papers addressing drug utilization in children (Table 2). The data were summarized by calculating a weighted average for each drug category with weights proportional to the number of prescriptions (Table 3). Drugs most often used by children are respiratory drugs, anti-infectives for systemic use and dermatologicals.

The pattern of drug use in adults based on sales over the last 12 months to May 2005 (Table 4) shows that drugs used for central nervous system, cardiovascular, alimentary tract and metabolism disorders make up over $50 \%$ of the market.

\section{Discussion}

The introduction of the pediatric exclusivity laws in the USA has led to pediatric drug trials for 135 drugs tested in the past eight years. Over 300 studies were performed with over 40,000 pediatric patients participating. Based on these data, the FDA claims "the pediatric exclusivity provision has done more to generate clinical studies and useful prescribing information for the pediatric population than any other regulatory or legislative process to date" [20]. The EU Commission and other policy makers see a rapid adaptation of similar legislation in Europe essential to boost pediatric drug research in the EU as soon as possible $[1,3$, 19]. Although it is true that more pediatric studies have been done, we question the content of the research.

A major discrepancy is apparent between the drug prescription pattern in children and the drugs granted pediatric exclusivity. The majority of drugs granted pediatric exclusivity are rarely used by children, and drugs that are frequently used by children are underrepresented in the pediatric studies to obtain exclusivity. This difference is not accounted for by the licensing status of the used drugs. For instance, in general practice, $37 \%$ of the prescriptions of respiratory drugs are still used in an unlicensed or offlabel manner [27]. This suggests that the pediatric studies did not address the real needs in pediatric drug development. Whilst the pediatric exclusivity scheme has stimulated pediatric research quantitatively, the nature of the scheme has led to priorities for the type of research that are largely driven by the adult market for medicines rather than by the needs of the pediatric population. An important built-in motive in the stimulation program for performing pediatric studies is the financial benefit gained from the

Table 2 Characteristics of included studies on pediatric drug utilization

\begin{tabular}{|c|c|c|c|c|}
\hline Author (year) & Setting & $\begin{array}{l}\text { Population } \\
\text { size }\end{array}$ & $\begin{array}{l}\text { Age range } \\
\text { (y) }\end{array}$ & $\begin{array}{l}\text { Number of } \\
\text { prescriptions }\end{array}$ \\
\hline Niclasen [14] (1995) & Pharmacy dispensing records in-and outpatients & 1,704 & $0-14$ & 5,876 \\
\hline Rokstad [21] (1997) & Prescriptions of general practitioners & a & $0-19$ & 8,215 \\
\hline Thrane [28] (1999) & Pharmacoepidemiological prescription database outpatients & 48,091 & $0-15$ & 154,189 \\
\hline Schirm $^{\mathrm{b}}$ [24] (2000) & Pharmacy dispensing records outpatients & 15,001 & $0-16$ & 373,925 \\
\hline Lewis [12] (2001) & Prescriptions pediatric outpatients & 12,628 & $0-16$ & 33,140 \\
\hline Pandolfini [16] (2002) & Prescriptions general pediatric hospitals & 1,325 & $0-14$ & 4,265 \\
\hline Schirm [23] (2003) & Pharmacy dispensing records outpatients & 18,943 & $0-16$ & 66,222 \\
\hline Ufer [30] (2003) & Pharmacy dispensing records outpatients & 357,784 & $0-16$ & 644,817 \\
\hline Sanz [22] (2004) & Prescriptions outpatients by GPs and pediatricians & 12,264 & $0-14$ & 27,486 \\
\hline
\end{tabular}

a Not stated

b Not included in weighted average due to presentation of data in paper (percentage of children using a drug category). 
Table 3 Drug utilization pattern in children

\begin{tabular}{|c|c|c|}
\hline Drug category & $\begin{array}{l}\% \text { of } \\
\text { prescriptions }\end{array}$ & Frequent used drug classes \\
\hline Respiratory system & $30 \%$ & $\begin{array}{l}\text { Drugs for obstructive airway disease } \\
\text { Nasal preparations } \\
\text { Cough and cold preparations } \\
\text { Antihistamines for systemic use }\end{array}$ \\
\hline General anti-infectives, systemic & $28 \%$ & Antibacterials for systemic use \\
\hline Dermatologicals & $12 \%$ & $\begin{array}{l}\text { Antifungals for dermatological use } \\
\text { Emollients and protectives } \\
\text { Corticosteroids, dermatological preparations }\end{array}$ \\
\hline Sensory organs & $7 \%$ & $\begin{array}{l}\text { Ophtalmologicals } \\
\text { Otologicals }\end{array}$ \\
\hline Central nervous system & $4 \%$ & $\begin{array}{l}\text { Analgesics/ antipyretics } \\
\text { Psychostimulants, agents used for ADHD and } \\
\text { nootropics } \\
\text { Anti-epileptics }\end{array}$ \\
\hline Hormones & $3 \%$ & Corticosteroids, for systemic use \\
\hline Blood and blood forming organs & $3 \%$ & Vitamin $\mathrm{K}$ \\
\hline Alimentary tract and metabolism & $2 \%$ & $\begin{array}{l}\text { Drugs for peptic ulcer and gastro-oesophageal } \\
\text { reflux disease } \\
\text { Insulins and analogues }\end{array}$ \\
\hline Musculo-skeletal system & $2 \%$ & $\begin{array}{l}\text { Anti-inflammatory and anti-rheumatic } \\
\text { products, non-steroids }\end{array}$ \\
\hline Genito-urinary system and sex-hormones & $2 \%$ & Hormonal contraceptives for systemic use \\
\hline Cardiovascular system & $1 \%$ & Diuretics \\
\hline Other & $<1 \%$ & \\
\hline Total & $105 \%$ (exceed & $100 \%$ due to rounding) \\
\hline
\end{tabular}

exclusivity provision. The drugs granted pediatric exclusivity include 5 out of the "Top 10" prescription drugs with the highest sales figures in North America in 2005: atorvastatin (Lipitor), simvastatin (Zocor), omeprazole (Nexium), lansoprazol (Prevacid), and sertraline (Zoloft). Sales of these 5 drugs amounted to $\$ 24.1$ billion US in 2005 [9]. Extension of the SPC on the basis of pediatric exclusivity has also been granted to other adult best-selling

Table 4 Drug utilization patterns in adults, according to the drug sales in North America over the period May 2004-May 2005

\begin{tabular}{ll}
\hline Drug category & Adult prescriptions \\
\hline Central nervous system & $23 \%$ \\
Cardiovascular system & $19 \%$ \\
Alimentary tract and metabolism & $14 \%$ \\
Respiratory system & $9 \%$ \\
General anti-infectives, systemic & $8 \%$ \\
Musculo-skeletal system & $6 \%$ \\
Genito-urinary system and sex-hormones & $6 \%$ \\
Other & $2 \%$ \\
Antineoplastic and immunomodulating agents & $4 \%$ \\
Dermatologicals & $3 \%$ \\
Blood and blood forming organs & $3 \%$ \\
Sensory organs & $2 \%$ \\
Total & $100 \%$ \\
\hline
\end{tabular}

drugs, such as pravastatine, enalapril, metformin, amlodipine, paroxetine, fluoxetine, and rofecoxib (currently withdrawn). It is thus clear that the patent extension has an enormous financial benefit for the pharmaceutical companies, which easily outweighs the cost of the average pediatric trial [1]. This is not only the case for best-selling drugs but also for drugs with a smaller market share. A Tufts University report indicates that an estimated \$35 million US in undiscounted profits per drug can be earned by obtaining pediatric exclusivity based on median 2004 sales for all pediatric exclusivity drugs after accounting for costs and market protection extensions [29]. Although the increased profit was intended by the legislator, we doubt if the other intention, which aimed at providing data to reduce the volume of drugs taken by children that are off-label or unlicensed, has also been met.

Our approach to define essential drugs for children by volume and by number of children that need a certain medicine is incomplete, as indications and severity of the conditions for which the drug is prescribed also play an important role [10]. Secondly, the method employed in our literature search may have introduced some bias toward outpatient drug consumption, thus underestimating the use of, for example, anesthetic or cardiovascular drugs. Clearly, hypertension or lipid disorders occur in children, and 
knowledge about these drugs in this population is important. However, these conditions are certainly not major causes of morbidity, and subsequent drug use in children and the research priorities lie elsewehere.

Furthermore, there are specific issues in pediatric clinical pharmacology that have remained unaddressed by the current product-related approach. First, the age distribution of the children participating in the trials does not reflect the actual medical needs. Drug use in children follows a pattern, with a relatively high percentage of children using a prescription drug in the first year of life [24] while the proportion of off-label and unlicensed drug use is highest $(\sim 90 \%)$ in the vulnerable group of neonatal ICU patients [5]. These data are not reflected in the participation in the trials to obtain pediatric exclusivity, with neonates and infants being included in, respectively, 14 and $39 \%$ of the study groups. In fact, it is surprising to see that the majority of applications included children of a wide age range, thereby ignoring the delineation of age groups as defined in the ICH guidelines. This is problematic, as in the pediatric population significant age-related differences may exist in the pharmacokinetics and the effects of drugs [11]. Secondly, the effects of drugs (that are intended for chronic use) on development and maturation of children are largely unknown, but this issue has hardly been addressed. Third, off-label drugs are hardly or not studied. Only ten drugs in this category are under consideration for study by pharmaceutical companies (FDA website). From these ten drugs, six already have been refused by industry for studying, and have been referred to the National Institutes of Health to obtain the necessary information for rational use in pediatric populations. These clinical trials are at the moment awaiting funding [13, 18]. Surprisingly, in the same Tufts study that reports on a profit of $\$ 35$ million US per drug granted exclusivity, it is also suggested that the current incentives for studying non-patent protected drugs are too low [29].

Finally, methodological research has remained underfunded by this approach. Any expansion of research will require specialized techniques that allow samples and data to be obtained in children with minimal discomfort and risk. For instance, most pharmacokinetic assays require an amount of blood that is too large for the average neonate, so highly sensitive assays need to be developed. Accurate assessment of drug effects on neuro-development and behavior also require further development, independently of studies with particular compounds.

The recently approved EU guidelines contain differences from the USA that may remedy some of the deficiencies indicated. It contains a section for the stimulation of offpatent drugs that can be granted a special label (PUMA), and data protection if data necessary to establish safety, quality and efficacy in children are submitted. The
'Medicines Investigation for the Children of Europe' program, funded by the EU, will be created to stimulate research of off-patent drugs. The proposed establishment of a Pediatric Committee, operating within the European Medicines Agency, will guard study of significant drugs for children and avoid unnecessary studies, provide free advice to industry, and stimulate long-term pharmacovigilance. It will also play a role in the implementation of the requirement for industry to submit data they already hold on use of their medicines in children. New drugs will not be granted Marketing Authorisation unless the need for pediatric research has been waived by the Pediatric Committee, or deferral of initiation or completion of an already approved Pediatric Investigation Plan has been agreed to by this committee. In addition, an EU network of investigators and trial centers will be formed [1]. Although elements of this network are now beginning to form, their funding is unclear and certainly not at the level provided to the patent holders by a patent extension. Also, it is not immediately clear why the EU measures will deliver, when this was not achieved with the formation of Pediatric Pharmacology Research Units and the oversight of research priorities by the FDA in the USA.

In conclusion, the schemes implemented in the US generated new knowledge and led to the rapid development of an infrastructure to carry out pediatric drug trials. Although these are certainly positive developments, we do believe that the findings of this survey warrant additional efforts to stimulate research on drugs used more frequently by children, and generally applicable methodological research, as at least the short-term effect of these initiatives seems to have drawn the focus of industry-sponsored research to the most profitable part of the market. The funding of the research we propose should not be problematic. The pediatric exclusivity schemes generate a flow of public money to the sponsoring drug companies because generic replacement and price reductions are postponed. There is no particular reason why these public funds could not be at least partly applied in an alternative manner.

\section{References}

1. Arlett P (2005) Proposed regulation on medicinal products for paediatric use. Overview and explanation of the proposal. http:// pharmacos.eudra.org/F2/Paediatrics/docs/overview $\% 20$ and $\%$ 20explanation $\% 20$ of $\% 20$ the $\% 20$ proposal\%201.pdf (accessed July 27, 2005)

2. Caldwell PH, Murphy SB, Butow PN, Craig JC (2004) Clinical trials in children. Lancet 364:803-811

3. Commission of the European communities (2004) Proposal for a regulation of the European parliament and of the council on medicinal products for paediatric use and amending Regulation (EEC) No 1768/92, Directive 2001/83/EC and Regulation (EC) No $726 / 2004$, Brussels 
4. Ceci A, Felisi M, Catapano M, Baiardi P, Cipollina L, Ravera S, Bagnulo S, Reggio S, Rondini G (2002) Medicines for children licensed by the European Agency for the Evaluation of Medicinal Products. Eur J Clin Pharmacol 58:495-500

5. Conroy S, McIntyre J, Choonara I (1999) Unlicensed and off label drug use in neonates. Arch Dis Child Fetal Neonatal Ed 80: F142F144

6. Drugs@FDA. http://www.accessdata.fda.gov/scripts/cder/drug satfda/index.cfm (accessed August 23, 2006)

7. IMS World Review (2004) IMS Health, Fairfield, Connecticut, USA

8. IMS Health Retail Drug Monitor (2004) IMS Health, Fairfield, Connecticut, USA

9. IMS National Sales Perspectives (2005) IMS Health, Fairfield, Connecticut, USA

10. Kauffman RE (1999) Essential drugs for infants and children: North American perspective. Pediatrics 104:603-605

11. Kearns GL, Abdel-Rahman SM, Alander SW, Blowey DL, Leeder JS, Kauffman RE (2003) Developmental pharmacology-drug disposition, action, and therapy in infants and children. N Engl J Med 349:1157-1167

12. Lewis MA, Kuhl-Habich D, Von Rosen J (1994) Drug use and adverse event monitoring in German children. Int $\mathrm{J}$ Clin Pharmacol Ther 39:507-512

13. Murphy D (2004) The role of the FDA in pediatric research [presentation], presented at the Glaser Pediatric Research Network Symposium. Boston, USA, July http://www.fda.gov/cder/pediatric/ presentation/Glaser-July16-2004_Murphy_Dianne/

14. Niclasen BV, Moller SM, Christensen RB (1995) Drug prescription to children living in the Arctic. An investigation from Nuuk, Greenland. Arctic Med Res 54(Suppl 1):95-100

15. Pandolfini C, Bonati M (2005) A literature review on off-label drug use in children. Eur J Pediatr 164:552-558

16. Pandolfini $C$, Impicciatore $P$, Provasi D, Rocchi F, Campi R, Bonati M (2002) Off-label use of drugs in Italy: a prospective, observational and multicentre study. Acta Paediatr 91: 339-347

17. Pediatric Exclusivity Labeling Changes. http://www.fda.gov/cder/ pediatric/labelchange.htm (accessed August 23, 2006)

18. Progress in Implementing the Best Pharmaceuticals for Children Act (BPCA). U.S. department of health and human services, National Institutes of Health (NIH), National Institute of Child Health and Human Development (NICHD). htpp://www.nichd.
nih.gov/bpca/documents/progress_implementing_BPCA.pdf (accessed August 20, 2005)

19. Ramet J (2005) What the paediatricians need-the launch of paediatric research in Europe. Eur J Pediatr 164:263-265

20. Roberts R, Rodriguez W, Murphy D, Crescenzi T (2003) Pediatric drug labeling: improving the safety and efficacy of pediatric therapies. JAMA 290:905-911

21. Rokstad K, Straand J, Fugelli P (1997) General practitioners' drug prescribing practice and diagnoses for prescribing: the More \& Romsdal Prescription Study. J Clin Epidemiol 50:485-494

22. Sanz E, Hernandez MA, Ratchina S, Stratchounsky L, Peire MA, Lapeyre-Mestre M, Horen B, Kriska M, Krajnakova H, Momcheva H, Encheva D, Martinez-Mir I, Palop V (2004) Drug utilisation in outpatient children. A comparison among Tenerife, Valencia, and Barcelona (Spain), Toulouse (France), Sofia (Bulgaria), Bratislava (Slovakia) and Smolensk (Russia). Eur J Clin Pharmacol 60:127134

23. Schirm E, Tobi H, de Jong-van den Berg LT (2003) Risk factors for unlicensed and off-label drug use in children outside the hospital. Pediatrics 111:291-295

24. Schirm E, van den Berg P, Gebben H, Sauer P, de Jong-van den Berg L (2000) Drug use of children in the community assessed through pharmacy dispensing data. Br J Clin Pharmacol 50:473-478

25. Smyth RL, Weindling AM (1999) Research in children: ethical and scientific aspects. Lancet 354(Suppl 2):SII21-SII24

26. Summaries of Medical and Clinical Pharmacology Reviews of Pediatric Studies. http://www.fda.gov/cder/pediatric/Summaryreview. htm (accessed August 23, 2006)

27. 't Jong GW, Eland IA, Sturkenboom MC, van den Anker JN, Strickerf BH (2004) Unlicensed and off-label prescription of respiratory drugs to children. Eur Respir J 23:310-313

28. Thrane N, Sorensen HT (1999) A one-year population-based study of drug prescriptions for Danish children. Acta Paediatr 88:1131-1136

29. Tufts Center for the Study of Drug Development (2005) U.S. pediatric studies incentive led to new labeling for nearly 100 drugs-Impact Report Volume 7, Number 4, July/August 2005

30. Ufer M, Rane A, Karlsson A, Kimland E, Bergman U (2003) Widespread off-label prescribing of topical but not systemic drugs for 350,000 paediatric outpatients in Stockholm. Eur J Clin Pharmacol 58:779-783 